\title{
Evidence-based progressive passage to reopening American societies post COVID-19
}

\section{Abstract}

Introduction: In the United States, the total number of confirmed reported cases of Covid-19 had reached 6.45 million with a total death of 193, 246 as of Sept 6, 2020. Significant efforts have been invested to flatten the curve and control new cases appearing in the societies. Meanwhile, the governments has imposed a lockdown with the objective of controlling the transmission of the virus. The re-opening of societies is challenging and might involve threats, many of them remain unseen.

Methods: We present here the validation of a Lateral Flow Immunochromatographic Assay in comparison with RT-PCR and describe a dynamic scenario to un-locking and re-opening societies using an evidence-based design, suggested by an algorithm of screening using RT-PCR and antibodies in a large population.

Results and Conclusion: In the absence of highly reliable vaccine and/ or treatment for Covid-19, the decision to go back to work or stay at home remains controversial and risky. Controversial because our limited knowledge of the virus and risky in view of the uncertainty of acquired immunity. Attempts based on multi-analytical approaches, such as the algorithm presented here, are required for a better management and a more flexible fine tuning of re-opening societies.

\section{Keywords}

Covid-19; Immuno-chromatographic Assay; RT-PCR; USA Population.
Ziad Daoud ${ }^{1,2}$ Jesse McLeod ${ }^{1,2}$, Offiang F. Ikpatt ${ }^{1,2}$, Magdalena Perez ${ }^{1,2}$, Marcus Atkins ${ }^{2}$, Tracy Speier², David Stockman 1,2

1 Department of Clinical Microbiology and Infection Prevention, Michigan Health Clinic, 4707 McLeod Dr., Saginaw, MI 48604, USA.

2 Public Health Institute of Science, Epidemiology, and Research, 2200 Pennsylvania Ave, NW $4^{\text {th }}$ Floor East. Washington DC 20037, USA.

\section{Contact information:}

Dr. David Stockman.

ĐDStockman@chs-mi.com

\section{Introduction}

As of September 6, 2020, the virus SARS-Cov2 had resulted in more than $27,282,417$ infections and 887,277 deaths worldwide. The disease caused by this virus, COVID-19 has now been reported on every continent. In the United States, the total number of confirmed reported cases of Covid-19 
had reached 6.45 million with a total death of 193, 246 and a total confirmed recoveries of 3,725,970 cases (https://worldometers.information). The medical, social, and economic impacts of this pandemic have been so far unexpectedly devastating for the whole world. The main interest of the countries, as recommended by epidemiologists and specialists, has been for the time being how to flatten the curve and control new cases appearing in the societies. Meanwhile, governments are/have been imposing a lockdown in their countries with the objective of controlling better the transmission to non-infected people, and therefore, enable hospitals and health authorities to provide an optimal health care in view of the severe limitation and shortage of reanimation material and Personal Protective Equipment. Attempts to find the "best" available drug have identified so far some molecules including Hydroxycholoroquine, Remdisivir, and others [1, 2]. On the other hand, researchers in different countries are working hard for thedevelopment of new vaccines $[3,4]$, however, a successful vaccine might not be available before the year 2021.

Physical (social) distancing has been so far considered as the only affordable measure despite many objections and incompliances. The main purpose of a lockdownis to reduce the transmission and therefore, the reproduction of the virus, in other terms, to reduce the number of people each confirmed case infects $[5,6]$

Lockdown and confinement aim to reverse epidemic growth, reducing therefore the case numbers to low levels by social distancing [5]. In absence of a strict lockdown that creates quarantines separating people who are vulnerable to the infection and people who are not infected from those who harbor the virus and shedding it in their respiratory secretions, one can expect a very high rate of mortality. However, an end to lockdown is many weeks away for some nations, but decisions on how to do it need to be made now so preparations can be made and communicated clearly.
Being an emergency measure, the lockdown is only transitory and "Un-locking" countries is a must regardless how long it would take. It needs to be done carefully with a strict strategy that takes into account the epidemiologic characteristic of the infection, the socio-economic needs of the society, as well as many other cultural, economic, and health related details [6] Such strategies should make use of current technologies using contact tracing, protective gear and aggressive testing of post-virus immunity. Obviously, unlocking without a proper strategy might have serious and severe drawbacks, where the most likely outcome might be that the epidemic starts again. This should be clearly distinguished from a second wave that normally appears after the re-opening of societies; however, if a wellcontrolled re-opening is done, the second wave of viral infection would be much less aggressive and much better handled.

Here, we describe and proposes a dynamic scenario to un-locking and re-openingsocieties using an evidence-based design, suggested by an algorithm of screening using RT-PCR and antibodies in a large population of Saginaw-Michigan.

Michigan Health Clinics, a multispecialty health care provider in the Great Lakes Bay Region, has been actively involved in providing Covid-19 testing to the citizens of Michigan since the beginning of the crisis. Lately, our services were extended in a significant way to provide large Drive-In testing of SARS-Cov2 of the citizens of Saginaw; so far, the screening reached 1572 people. The algorithm of testing is based on the latest developments in SARS-Cov2 detection using Real Time-Polymerase Chain Reaction (RT-PCR), as well as serological detection of antibodies against the virus (IgG and IgM) by Lateral Flow Immunochromatographic Assays.

The algorithm of screening is based on the diagram in Figure 1. Briefly, a screening using Lateral Flow Immuno-chromatographic Assay is performed on the plasma of all symptomatic and asymptoma- 
Figure 1: Asymptomatic and symptomatic Patients.

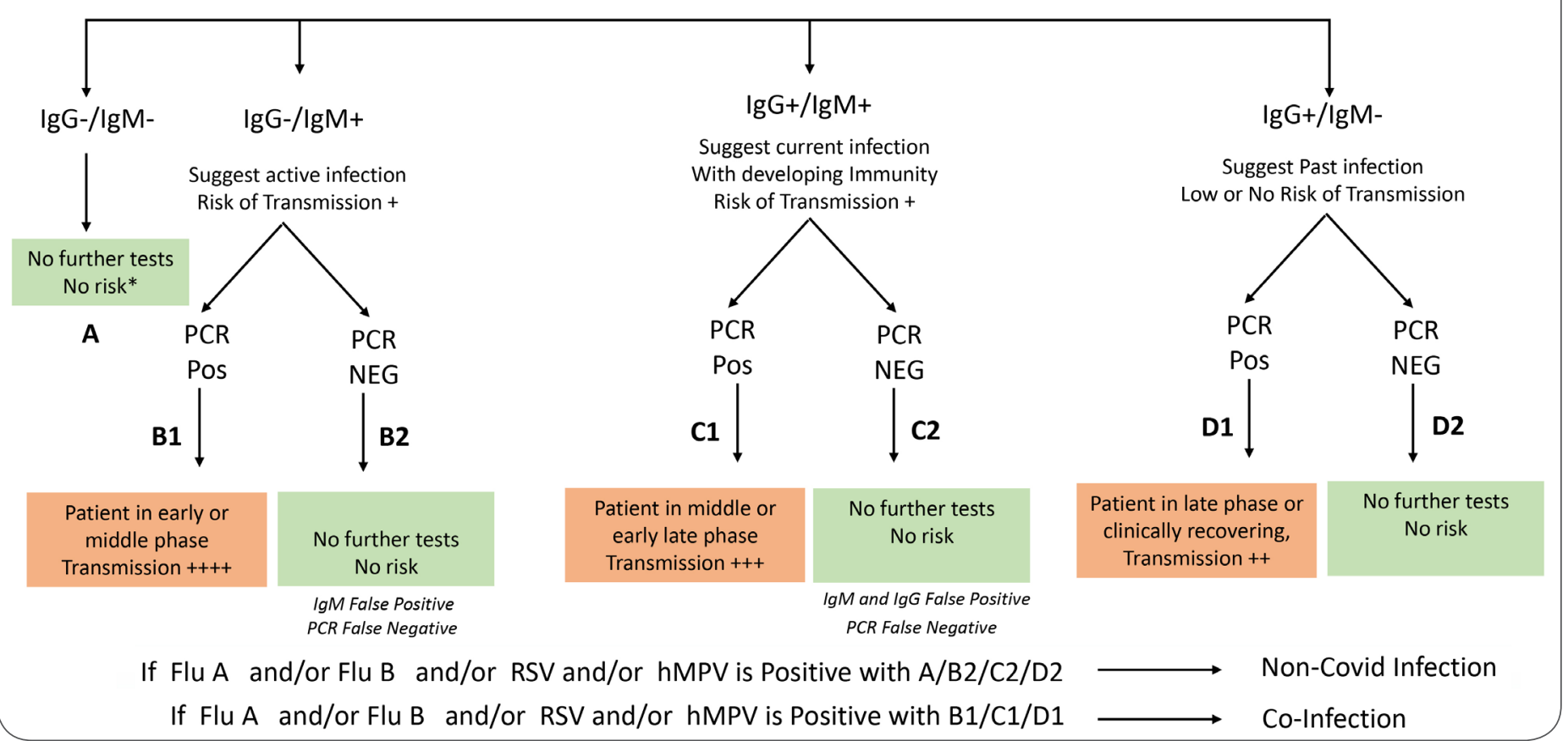

tic people. The test was validated in our labs with a sensitivity and specificity rates were determined as compared to RT-PCR testing (Section III below). As shown in this algorithm, depending on the results of $\operatorname{lgM}$ and $\lg G$, the next step of testing is decided. RT-PCR (according to the instructions of (DC) is performed on nasopharyngeal swab from all patients who tested positive for at least one the antibodies. Symptomatic patients were also tested for Influenza A, Influenza B, RSV, and hMPV using Helicase Dependent Amplification Assays (SolanaQuidel, USA).

\section{Material and Methods}

\section{Lateral Flow Immunochromatographic Assay (Healgen kit) and RT-PCR testing} The detection of Immunoglobulins ( $M$ and $G$ ) uses the principle of immunochromatography: the separation of components in a mixture through a medium using capillary force and the specific and rapid binding of an antibody to its antigen. The detection of each antibody is performed on a separate cas- sette. Each cassette is a dry medium that has been coated separately with novel coronavirus $\mathrm{N}$ protein (" $\mathrm{T}$ " test line) and goat anti-chicken IgY antibody (" $\mathrm{C}$ " control line). Two free colloidal gold-labeled antibodies, mouse anti-human $\operatorname{lgM}(\mathrm{mlgM})$ and chicken IgY, are in the release pad section (S), also Two free colloidal gold-labeled antibodies, mouse anti-human $\lg G(\mathrm{mlg} G)$ and chicken lgY, are in the release pad section (S). Once diluted serum, plasma, or whole blood is applied to the release pad section, the mlgM or mlgG antibody will bind to coronavirus IgM antibodies if they are present, forming an IgM-IgM complex. The sample and antibodies will then move across the cassette's medium via capillary action. If coronavirus IgM antibody is present in the sample, the test line $(T)$ will be bound by the IgM-IgM complex and develop color. If there is no coronavirus IgM antibody in the sample, free mlgM will not bind to the test line $(\mathrm{T})$ and no color will develop. The free chicken IgY antibody will bind to the control line $(C)$; this control line should be visible after the detection step as this confirms that the kit is working properly. 


\section{Sample}

EDTA plasma was used the preferred specimen. Specimens not centrifuged and tested within two hours of collection were stored at $2-8^{\circ} \mathrm{C}$ for up to 7 days.

\section{Reagents}

SARS-Cov2 lgM/lgG Antibody Detection kit from Healgen was used. The detection cassettes included: Novel coronavirus N protein, Goat anti-chicken IgY antibody, Colloidal gold-labeled mouse anti-human IgM antibody and mouse anti-human $\lg G(S)$, and Plastic pipette dropper

\section{Description of Test and Reporting of Results}

The LFIA test was performed according to the manufacturer's instruction and the results were interpreted either as Negative IgM, Negative lgG: Negative results: No evidence of an increase in human $\lg M$ and $\lg G$ production against SARS-Cov2. A negative or non-reactive result might indicate a state of no infection or an incubation period of the virus. In case of suspicious exposure, the patient should be advised to repeat the test in 7 to 10 days. A negative result can also be due to a delayed immune response by the patient.

A Positive IgM, Negative IgG or Non-reactive: This result can indicate an early stage of SARSCov2 infection. The absence of IgG indicates that the patient did not develop acquired immunity yet.

A. Positive IgM, Positive IgG. IgM positive and IgG positive: This result suggests either an active or an early recovery stage of the infection with SARS-Cov2.

B. Negative IgM, Positive IgG. IgM negative and IgG positive: This result indicates a late stage or a past infection with SARS-Cov2. This suggests that an acquired immunity has developed to the virus.
For molecular testing, a naso-pharyngeal swab was obtained from the same patient RT-PCR experiments were not performed in our lab, they were sent to a reference lab and results were communicated within 24 hours.

\section{Performance evaluation of LFIA}

A 90 whole blood samples were tested after the approval of the Institution Review Board (IRB). The blood samples were transferred from tubes with anticoagulant (EDTA) previously collected from patients tested for Covid19 with PCR. Since our intention was to perform the test on plasma from patients, our validation procedure addressed only plasma samples. No validation was done concerning serum, whole blood, or capillary blood samples.

\section{Sensitivity and specificity determination}

Both sensitivity and Specificity were determined as per the following formulas:

Sensitivity $\%=100 \times$ [True Positive/(True Positive + False Negative)]

Specificity $\%=100 \times$ [True negative / (True Negative + False Positive)].

\section{Accuracy and Limit of detection (LoD)}

Three serial dilutions from three different patients' plasma were prepared separately. The dilution interval from one dilution to another was the double leading to decreasing concentrations by half.

\section{Detection of antibodies was performed on all the dilutions}

Intra-assay validation (Intra-assay

Repeatability)

Eight plasma samples were run in 5 repetitions each. The table does not show the Means, Standard Deviations, and Coefficients of Variation because the test is either positive or negative

\section{Inter-assay precision (Inter-assay Repeatability)}

Inter-assayassay precision shows the reproducibility between assays done on different days. 
Inter-assay precision is typically $<10 \%$. This ensures the results obtained will be consistent over time and between kits. The table does not show the Means, Standard Deviations, and Coefficients of Variation because the test is either positive or negative

A. Cross Reactivity Assays was evaluated for IgM and IgG SARS-Cov2 detection rapid test using plasma samples from patients with documented antibodies against the below listed pathogens.

B. Class Specificity: Class specificity for Human IgM $(0.4 \mathrm{mg} / \mathrm{ml}$ of Human IgM Purified Immunoglobulin- Biorad) to cross react and produce false positive results for IgG was evaluated using 5 Patients' plasma with IgG negative. Class specificity of Human IgG (8 $\mathrm{mg} / \mathrm{ml}$ of Natural Human Ig -Biorad) to cross react and produce false positive results for IgM was evaluated using 5 Patients' plasma with IgM negative. Each sample was tested in duplicate. The ability of Human IgM 0.4 mg/ $\mathrm{ml}$ and Human IgG $8 \mathrm{mg} / \mathrm{ml}$ to compete and produce false negative results for lgM or IgG was evaluated using 5 patients' plasma (IgM positive IgG positive). Each sample was tested in duplicate

C. Potentially interfering substances were tested after preparing low titer SARS-CoV2 antibody positive serum samples and SARS-Cov2 antibody negative serum samples. Aliquots of both preparations were spiked with potentially interfering substances to approximate the indicated concentrations and tested triplicates.

\section{Testing Algorithm}

A testing algorithm was developed taking into account the high sensitivity and specificity of the LFIA in conjunction with the PCR results.

\section{Results}

\section{Clinical evaluation}

Clinical Performance: Sensitivity and Specificity

In Table 1 results show limitation of testing 90 samples (43 positive samples and 47 Negative samples by RT-PCR). Clinical Performance: The conclusion is as below. A very good coincidence rate was found between the two methods. Positive coincidence rate is $90.7 \%$, negative coincidence rate is $97.8 \%$, and total coincidence rate is $94.4 \%$. Table 2 \& 5.

Table 1. Sensitivity and specificity of the tested combined $\operatorname{lgM} / \mathrm{lgG}$ determination method versus the PCR method.

\begin{tabular}{|c|c|c|c|c|}
\hline & \multicolumn{2}{|c|}{ Reference Method RT-PCR } & \multirow{2}{*}{ Total } \\
\hline & & + & - & \\
\hline \multirow{2}{*}{ LFIA kit } & + & 39 & 1 & 40 \\
\hline & - & 4 & 46 & 50 \\
\hline Total & & 43 & 47 & 90 \\
\hline
\end{tabular}

Clinical Accuracy of Kit 2 alone on a selection of 73 Positive and 52 Negative patients

\begin{tabular}{l|l} 
Sensitivity & $90.7 \%$ \\
Specificity & $97.8 \%$ \\
\hline Agreement, Total Agreement & $94.4 \%$
\end{tabular}

Table 2. Sensitivity and specificity of the separate and combined $\operatorname{lgM} / \lg G$ determination method versus the PCR method. Sensitivity and specificity of tested antibodies, and accuracy and Limit of detection (LoD) for $\lg M$ and $\lg G$.

\begin{tabular}{|l|c|c|c|}
\hline Domains/Facets & IgM alone & IgG alone & Combined \\
\cline { 2 - 4 } & $\%$ & $\%$ & $\%$ \\
\hline $\begin{array}{l}\text { Sensitivity } \\
\text { PPA }\end{array}$ & 83.7 & 85.7 & 90.7 \\
\hline $\begin{array}{l}\text { Specificity } \\
\text { NPA }\end{array}$ & 100 & 97.8 & 97.8 \\
\hline
\end{tabular}


Table 3. Dilutions of the initial plasma*.

\begin{tabular}{|l|c|c|c|c|c|c|c|}
\hline \multicolumn{1}{|c|}{ D 3 } & D0 & D1 & D2 & D3 & D4 & D5 & D6 \\
\hline [ ] & 1 & 0.5 D0 & 0.25 D0 & 0.125 D0 & 0.062 D0 & 0.031 D0 & 0.016 D0 \\
\hline Vol Diluent mcl & 0 & 50 & 50 & 50 & 50 & 50 & 50 \\
\hline Vol trasf mcl & 0 & 50 & 50 & 50 & 50 & 50 & 50 \\
\hline Band Control & + & + & + & + & + & + & - \\
\hline Band IgM & + & + & + & - & - & - & - \\
\hline Band IgG & + & + & + & + & + & + & - \\
\hline
\end{tabular}

Table 4. Dilutions of the initial plasma*.

\begin{tabular}{|l|c|c|c|c|c|c|c|}
\hline \multicolumn{1}{|c|}{ D 29 } & D0 & D1 & D2 & D3 & D4 & D5 & D6 \\
\hline [ ] & 1 & 0.5 D0 & 0.25 D0 & 0.125 D0 & 0.062 D0 & 0.031 D0 & 0.016 D0 \\
\hline Vol Diluent mcl & 0 & 50 & 50 & 50 & 50 & 50 & 50 \\
\hline Vol trasf mcl & 0 & 50 & 50 & 50 & 50 & 50 & 50 \\
\hline Band Control & + & + & + & + & + & + & - \\
\hline Band IgM & + & + & + & - & - & - & - \\
\hline Band lgG & + & + & + & + & + & + & - \\
\hline
\end{tabular}

Table 5. Dilutions of the initial plasma*.

\begin{tabular}{|l|c|c|c|c|c|c|c|}
\hline \multicolumn{1}{|c|}{ D 99 } & D0 & D1 & D2 & D3 & D4 & D5 & D6 \\
\hline [ ] & 1 & 0.5 D0 & 0.25 D0 & 0.125 D0 & 0.062 D0 & 0.031 D0 & 0.016 D0 \\
\hline Vol Diluent mcl & 0 & 50 & 50 & 50 & 50 & 50 & 50 \\
\hline Vol trasf mcl & 0 & 50 & 50 & 50 & 50 & 50 & 50 \\
\hline Band Control & + & + & + & + & + & + & - \\
\hline Band lgM & + & + & + & - & - & - & - \\
\hline Band lgG & + & + & + & + & + & + & - \\
\hline
\end{tabular}

\section{Intra-assay validation}

The Intra-assay validation shows the reproducibility between tubes within one testing time. Data resulting from intra-assay validation helps ensure that samples run in different tubes of the same experiment will give comparable results. Eight plasma samples were run in 5 repetitions each. All tests gave the same results in 5 different tubes and cassettes as show in Table 6.

\section{Inter-assay precision (Inter-assay}

Repeatability)

Inter-assay precision shows the reproducibility between assays done on different days. Inter-assay precision is typically $<10 \%$. This ensures the results obtained will be consistent over time and between kits. All tests gave the same results over 5 consecutive days Table 7. 
Vol. 10 No. $3: 3$ doi: $10.3823 / 850$
Table 6. Intra-assay experiment showing the reproducibility between tubes within one testing time.

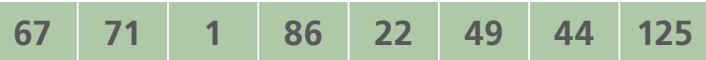

\begin{tabular}{|l|l|l|l|l|l|l|l|l|}
\hline & $\mathbf{6 7}$ & $\mathbf{7 1}$ & $\mathbf{1}$ & $\mathbf{8 6}$ & $\mathbf{2 2}$ & $\mathbf{4 9}$ & $\mathbf{4 4}$ & $\mathbf{1 2 5}$ \\
\hline IgM & & & & & & & & \\
\hline T1 & $\mathrm{P}$ & $\mathrm{P}$ & $\mathrm{N}$ & $\mathrm{P}$ & $\mathrm{N}$ & $\mathrm{P}$ & $\mathrm{N}$ & $\mathrm{N}$ \\
\hline T2 & $\mathrm{P}$ & $\mathrm{P}$ & $\mathrm{N}$ & $\mathrm{P}$ & $\mathrm{N}$ & $\mathrm{P}$ & $\mathrm{N}$ & $\mathrm{N}$ \\
\hline T3 & $\mathrm{P}$ & $\mathrm{P}$ & $\mathrm{N}$ & $\mathrm{P}$ & $\mathrm{N}$ & $\mathrm{P}$ & $\mathrm{N}$ & $\mathrm{N}$ \\
\hline T4 & $\mathrm{P}$ & $\mathrm{P}$ & $\mathrm{N}$ & $\mathrm{P}$ & $\mathrm{N}$ & $\mathrm{P}$ & $\mathrm{N}$ & $\mathrm{N}$ \\
\hline T5 & $\mathrm{P}$ & $\mathrm{P}$ & $\mathrm{N}$ & $\mathrm{P}$ & $\mathrm{N}$ & $\mathrm{P}$ & $\mathrm{N}$ & $\mathrm{N}$ \\
\hline IgG & & & & & & & & \\
\hline T1 & $\mathrm{P}$ & $\mathrm{P}$ & $\mathrm{N}$ & $\mathrm{P}$ & $\mathrm{N}$ & $\mathrm{P}$ & $\mathrm{N}$ & $\mathrm{N}$ \\
\hline T2 & $\mathrm{P}$ & $\mathrm{P}$ & $\mathrm{N}$ & $\mathrm{P}$ & $\mathrm{N}$ & $\mathrm{P}$ & $\mathrm{N}$ & $\mathrm{N}$ \\
\hline T3 & $\mathrm{P}$ & $\mathrm{P}$ & $\mathrm{N}$ & $\mathrm{P}$ & $\mathrm{N}$ & $\mathrm{P}$ & $\mathrm{N}$ & $\mathrm{N}$ \\
\hline T4 & $\mathrm{P}$ & $\mathrm{P}$ & $\mathrm{N}$ & $\mathrm{P}$ & $\mathrm{N}$ & $\mathrm{P}$ & $\mathrm{N}$ & $\mathrm{N}$ \\
\hline T5 & $\mathrm{P}$ & $\mathrm{P}$ & $\mathrm{N}$ & $\mathrm{P}$ & $\mathrm{N}$ & $\mathrm{P}$ & $\mathrm{N}$ & $\mathrm{N}$ \\
\hline
\end{tabular}

Table 7. Inter-assay precision showing the reproducibility between assays done on different days.

\begin{tabular}{|l|l|l|l|l|l|l|l|l|l|}
\hline \multicolumn{1}{|c|}{ Day } & $\mathbf{6 7}$ & $\mathbf{7 1}$ & $\mathbf{1}$ & $\mathbf{8 6}$ & $\mathbf{2 2}$ & $\mathbf{4 9}$ & $\mathbf{4 4}$ & $\mathbf{1 2 5}$ \\
\hline IgM & & & & & & & & \\
\hline 1 & $\mathrm{P}$ & $\mathrm{P}$ & $\mathrm{N}$ & $\mathrm{P}$ & $\mathrm{N}$ & $\mathrm{P}$ & $\mathrm{N}$ & $\mathrm{N}$ \\
\hline 2 & $\mathrm{P}$ & $\mathrm{P}$ & $\mathrm{N}$ & $\mathrm{P}$ & $\mathrm{N}$ & $\mathrm{P}$ & $\mathrm{N}$ & $\mathrm{N}$ \\
\hline 3 & $\mathrm{P}$ & $\mathrm{P}$ & $\mathrm{N}$ & $\mathrm{P}$ & $\mathrm{N}$ & $\mathrm{P}$ & $\mathrm{N}$ & $\mathrm{N}$ \\
\hline 4 & $\mathrm{P}$ & $\mathrm{P}$ & $\mathrm{N}$ & $\mathrm{P}$ & $\mathrm{N}$ & $\mathrm{P}$ & $\mathrm{N}$ & $\mathrm{N}$ \\
\hline 5 & $\mathrm{P}$ & $\mathrm{P}$ & $\mathrm{N}$ & $\mathrm{P}$ & $\mathrm{N}$ & $\mathrm{P}$ & $\mathrm{N}$ & $\mathrm{N}$ \\
\hline IgG & & & & & & & & \\
\hline 1 & $\mathrm{P}$ & $\mathrm{P}$ & $\mathrm{N}$ & $\mathrm{P}$ & $\mathrm{N}$ & $\mathrm{P}$ & $\mathrm{N}$ & $\mathrm{N}$ \\
\hline 2 & $\mathrm{P}$ & $\mathrm{P}$ & $\mathrm{N}$ & $\mathrm{P}$ & $\mathrm{N}$ & $\mathrm{P}$ & $\mathrm{N}$ & $\mathrm{N}$ \\
\hline 3 & $\mathrm{P}$ & $\mathrm{P}$ & $\mathrm{N}$ & $\mathrm{P}$ & $\mathrm{N}$ & $\mathrm{P}$ & $\mathrm{N}$ & $\mathrm{N}$ \\
\hline 4 & $\mathrm{P}$ & $\mathrm{P}$ & $\mathrm{N}$ & $\mathrm{P}$ & $\mathrm{N}$ & $\mathrm{P}$ & $\mathrm{N}$ & $\mathrm{N}$ \\
\hline 5 & $\mathrm{P}$ & $\mathrm{P}$ & $\mathrm{N}$ & $\mathrm{P}$ & $\mathrm{N}$ & $\mathrm{P}$ & $\mathrm{N}$ & $\mathrm{N}$ \\
\hline
\end{tabular}

\section{Cross Reactivity Assays}

No false positivity was found for IgM or IgG with the following organisms.

Human Coronavirus 229 E (alpha coronavirus)- 5 patients, Human Coronavirus NL63 (alpha corona- virus)- 5 patients, Human Coronavirus HKU1 (beta coronavirus)- 5 patients, Respiratory Syncytial Virus (IgG and $\lg M)-5$ patients

Human Coronavirus NL63+RSV- 2 patients, Human Coronavirus 229+RSV - 2 patients

Human Metapneumovirus (hMPV)- 5 patients, Parainfluenza virus $(1,3)-5$ patients, Influenza A (IgG and IgM)- 5 patients, Influenza B (IgG and IgM)- 5 patients, Hepatitis C Virus (IgG and IgM)- 4 patients, Hepatitis B Virus (IgG and IgM)- 4 patients, Haemophilus influenzae (IgG and IgM)- 5 patients, Chlamydia pneumoniae- 3 patients, HPV- 5 patients, HIV- 5 patients

\section{Class Specificity Assays}

We evaluated the potential for:

- Human lgM to cross react and produce false positive results for lgG: No false positivity for IgG was detected

- Human $\lg$ G to cross react and produce false positive results for IgM: No false positivity for IgM was detected

- Human IgM and Human IgG to compete and produce false negative results for IgM or lgG: No false negativity for IgM or IgG was detected

\section{Potentially interfering substances}

We prepared 1- low titer SARS-CoV2 antibody positive serum samples and 2- SARS-Cov2 antibody negative serum samples. We spiked aliquots of both preparations with one of the below substances to approximate the indicated concentrations and tested triplicates. No false positivity or false negativity was found with the following:

Hemoglobin (10 to $20 \mathrm{mg} / \mathrm{mL}$ ), Bilirubin Conjugated $<1 \mathrm{mg} / \mathrm{mL}$, Bilirubin Unconjugated $<1$ $\mathrm{mg} / \mathrm{mL}$, Ciprofloxacin $200 \mathrm{mg} / \mathrm{L}$, Cefotaxime 500 mg/L, Meropenem 200 mg/L, Imipenem $200 \mathrm{mg} / \mathrm{L}$, Amikacin $10 \mathrm{mg} / \mathrm{L}$, Amphotericin B $200 \mathrm{mg} / \mathrm{L}$. 
Vol. 10 No. 3:3 doi: $10.3823 / 850$

\section{The Testing Algorithm}

This algorithm of screening is recommended when screening large populations for many reasons:

1. Its high ability to assess whether the patient is infected or not and what is the state of the immune response (Figure 2)

2. It confirms any serology positive result by the use of RT-PCR, which is a sophisticated and expensive technique requiring highly trained personnel (Figure 3)

3. It saves RT-PCR material for needy cases since the algorithm does not recommend screening all patients using RT-PCR. In this context, sparing molecular kits is a must in such a scenario of pandemic in view of the high demand and shortage in availability (Figure 4)

\section{Discussion}

Arguably, the detection of immunoglobulins IgM and IgG has been questioned by many scientists and practitioners in view of the false negative results it can engender, the false positive results being much less do not pose a serious threat $[7,8]$. Serology looks for antibodies against SARS-Cov2 in the blood to determine if there has been an infection in the past. Antibodies are formed by the body to fight off infections. IgM is the first antibody that is formed against a germ, so it appears on tests first, usually within 1-2 weeks depending on the immunity of the patient. The body thenforms IgG, which appears on tests about 2 weeks after theillness starts. IgM usually disappears from the blood within afew months, but IgG can last for years [9]. In the "Testing Blueprint, Opening Up America Again" recently

\section{Figure 2.}

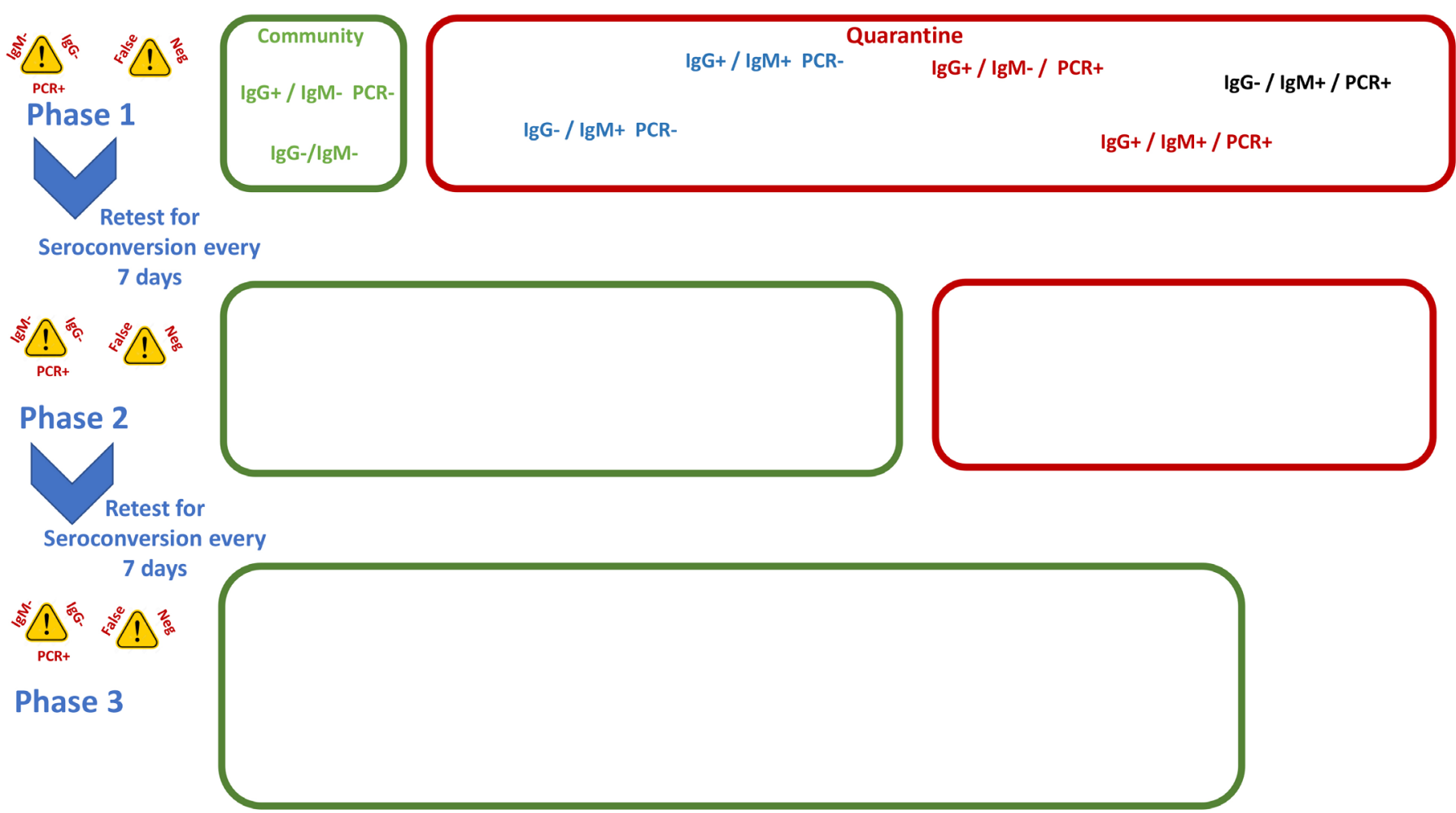


Figure 3.

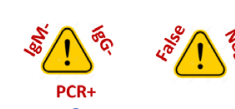

Phase 1

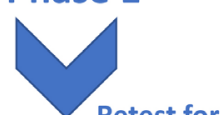

Retest for Seroconversion every 7 days

$\underbrace{5}_{\mathrm{PCR}+}$

Phase 2

$\int_{\text {Retest for }}$

Seroconversion every

$$
\text { PCR+ }
$$

Phase 3
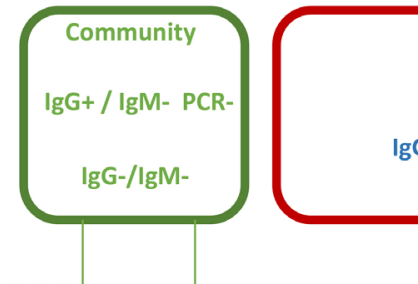
IgG+ / IgM+ PCR-

uarantine

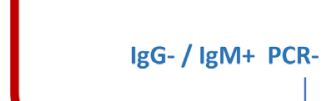

IgG+ / IgM- / PCR+

IgG- / IgM+ / PCR+

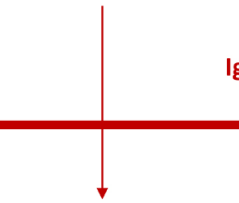

$\operatorname{lgG}+/ \operatorname{lgM}+/ \mathrm{PCR}+$

$\operatorname{lgG}+/$ IgM- / PCR+

Quarantine

IgG- / /gM+

IgG+ / IgM- PCR-

IgG+ / IgM- PCR-

IgG+ / IgM- PCR-

IgG+ / IgM+ / PCR+ 
issued [10]. The white house puts a plan for States to "maximize testing capability and protect health and safety during this pandemic and beyond". In this document, it was demonstrated that the use of two antibody tests rather than one dramatically improves the predictive value of a testing program, particularly in low prevalence environments. Higher positive predictive values (PPV) indicate that you most likely had the disease and produced antibodies in response. Higher negative predictive values (NPV) indicate you do not have antibodies and most likely have not had the disease [10].

The RT-PCR looks for the virus itself in the nose, throat, or other areas in the respiratory tract to determine if there is an active infection with SARSCov2 [11]. A positive PCR test suggests that the person being tested has an active COVID-19 infection. PCR testing only helps determine whether a person has an active infection at the time of testing. Unfortunately, it does not help determine who had an infection in the past. It also does not help determine which people who have been exposed to COVID-19 will develop active infection during the 2 weeks after exposure. In some people, the virus can only be found by PCR for a few days at the beginning of the infection, so the test might not find the virus if the swab is taken more than a few days after the illness starts.

All this led us to adopt a algorithm combining both RT-PCR and Serology testing in order to make a decision about past/present infection of individuals in large populations.

This screening algorithm might have 2 main limitations:

1. people who test negative for $\lg M$ and $\lg G$ are not tested by PCR, and this decisionis based on the high sensitivity of the technique (86.9\%), this might entail however the possibility for False Negatives. False positivity of the serology technique was considered very rare in view of the high associated specificity as validated by our lab (96.2\%). In addition, the combination of 2 Late- ral Flow Immunochromatographic Assays for the detection of immunoglobulins greatly improved sensitivity as well as Positive and Negative Predicted Values generated by this testing.

2. The PCR results might be erroneous sometimes giving rise to False Positive or False Negative results. Taking into account that re-opening societies cannot happen in absolute absence of the virus, entailing that the use of Personal Protective Equipment should not be discontinued during this process where a minimum of risk can exist, these two limitations were considered within the calculated risk. The below algorithm appears to be a more logical and feasible scenario to testing all the population using RT-PCR. This latter is practically not feasible in view of the price and severe shortage of molecular materialconsidered precious for hospitalized patients.

\section{Socialize or Quarantine: the process}

Obviously, people cannot be quarantined forever, not even for a very long time. The drawbacks of lockdown can lead to several challenges of different natures: economic, psychologic, financial, social, etc., at both individual as well as national levels [5]. Therefore, after the curve is "flattened", societies are expected to re-open and become able to "resuscitate" from the pandemic. In absence of an effective vaccine, acquiring Herd Immunity is not easy [6]. Such immunity is in general based on increasing the number of IgG seropositive people in a specific society by active/passive artificial/natural immunization. The re-opening can follow different scenarios that surely depend on the epidemiologic traits of the pandemic, the biologic features of the virus, mainly its mechanisms of transmission, in addition to several other social and economic parameters [12]. Taking all this into account, we developed aninteractive diagram allowing a progressive polyphasic passage from the state of Quarantine to the state of Open-Society in a smooth, slow, and safer way. This passage is based on a calculated 
estimation of the "Transmission potential" of the individual and a subsequent decision to "Quarantine" or "Inject" in the society. This evidence-based decision is made in the light of the SARS-Cov-2 detection in a nasopharyngeal swab by RT-PCR, and IgM/lgG detection in the patients' blood. Below, Figures 2, 3, and $\mathbf{4}$ illustrate a schematic description of this progressive decision making process.

One important information that the detection of the virus cannot provide, is the state of immunity of the patient, for this, serology testing is the only data that could tell whether the patient has acquired immunity or not. As well as any diagnostic investigation, the detection of immunoglobulins has limitations. For example, the body might not produce enough antibodies before 3 to 5 days of symptomatology or 5 to 7 days of viral entry in the human tissues, therefore, relying on serologic tests too soon after infection can yield false negative results. For this, the serologic testing should not be used alone as a primary method of diagnosing COVID-19 in an acutely ill patient. When a patient is symptomatic and experiencing the greatest viral replication, a molecular test is most useful for detecting the virus and determining a course of treatment.

\section{Evidence-based Reopening of societies}

Phases: After massive testing of the population, people can be categorized in 4 stages:

1. Stage 0 Very low Risk for Transmission (lgG+/ IgM-/PCR- and IgG-/lgM-)

2. Stage 1 Risk of Infectiousness (lgG+/lgM+/ PCR-, and IgG-/lgM+/PCR-)

3. Stage 2 Risk of Infectiousness (lgG+/lgM+/ $\mathrm{PCR}+$, and $\lg \mathrm{G}+/ \lg \mathrm{M}+/ \mathrm{PCR}+$ )

4. Stage 3 Risk of Infectiousness (IgG-/lgM+/ $\mathrm{PCR}+$ )

The majority of people testing negative for both $\operatorname{lgM}$ and IgG are considered virus-free, and therefore, safe in terms of disease transmission to others. However, if exposed to the virus, they might get infected and develop the disease. Subsequently, to keep them safe, the only category of patients that can interact with them are those patients who are IgG seropositive, meaning those who already developed IgGs and are not anymore positive of SARSCov2 by RT-PCR. There is however a risk in this combination, this risk is represented by the possible False negativity of $\operatorname{lgM}$ and IgG. Working with large populations cannot secure an absolute $100 \%$ of safety. The issue here is to bring the calculated risk as minimal as possible. Re-opening the society with only people who are IgG seropositivewill not bring a considerably high number of people to work and normal life, at least, not high enough for the regular functioning of the society. On the other hand, thelow rate of False negativitycan create a risk to the non-immune population, however, a manageable risk that can be controlled by the hospitals; such a risk is not expected to overwhelm the hospitals and health sector.

Phase 1

During this phase, Only people in Stage 0 are allowed to work. This will allow a good percentage of people to get back to work in a "safe" environment. The remaining people will remain in confinement until a sero-conversion is detected. When this happens they will be allowed to get back to work, always in a re-opening society respecting physical distancing ant use of mask. A Re-testing shall be performed after 7 days, then after 14 days, accordingly, people in Stage 1 will be allowed to go back to society when they convert into Stage 0 .

Phase 2

During this phase, the number of people going back to work is expected to keep increasing while less people will be quarantined as shown here below. Testing and Re-testing will continue after 7 and 14 days as described for phase 1 . The risk factors described in phase 1 remain the same in this phase 2 . Phase 3

During this phase, the number of people going back to work will keep increasing while less people will 
be quarantined as shown here below. Testing and Re-testing will continue after 7 and 14 days as described for phases 1 and 2. The risk factors described in phases 1 and 2 remain the same here.

\section{Special considerations}

Some populations will not be able to go back to normal life before a longer time, at least not before a suitable vaccine is developed. Among these, people under high risk of infection, patients with chronic diseases, elderly, etc. Patients testing positive for SARS-Cov2 need also to remain quarantined until the microbiological recovery is achieved.

In addition, returning to the normal life should be done wisely and progressively, in other terms, people should consider that risk remains there and should deal with each other on the basis of "possibly infectious". The already established rules, mainly wearing a mask, avoiding large social gatherings and events, keeping physical distance, etc. need to be respected and should not be ignored before a successful vaccine is made available. Time will be a major factor in unveiling the post-pandemic consequences, it is important to bear in mind that "Survival if for the fittest", in this case fitness can be provided by immunity rather than confinement. Governments, municipalities, and other authorities have the obligation of controlling and overseeing the re-opening of societies, imposing therefore a progressively increasing capacities over the different phases in restaurants, indoor ay outdoor activities, social gatherings, back-to-school, etc.

\section{References}

1. Colson P, Rolain JM, Lagier JC, et al. Chloroquinehydroxychloroquine as available weapons to fight COVID-19. Int J Antimicrob Agents 2020; 55(4):105932. Doi.org/10.1016/j. ijantimicag.2020.105932

2. Wang, M., Cao, R., Zhang, L. et al. Remdesivir and chloroquine effectively inhibit the recently emerged novel coronavirus (2019nCoV) in vitro. Cell Res 2020; 30: 269-271. Doi.org/10.1038/ s41422-020-0282-0

3. Yang, Z., Kong, W., Huang, Y. et al. A DNA vaccine induces SARS coronavirus neutralization and protective immunity in mice. Nature 2004;428,561-564. Doi.org/10.1038/nature02463
4. Ahmed SF, Quadeer AA, McKay MR. Preliminary Identification of Potential Vaccine Targets for the COVID-19 Coronavirus (SARS-Cov2) Based on SARS-CoV Immunological Studies. Viruses 2020; 12(3), 254. Doi: 10.3390/v12030254.

5. Wilder-Smith A, Freedman DO. Isolation, quarantine, social distancing and community containment: pivotal role for oldstyle public health measures in the novel coronavirus (2019nCoV) outbreak. J Trav Med 2020; 27(2) 2. Doi.org/10.1093/jtm/ taaa020

6. Interventions for Community Containment. https://www. cdc.gov/sars/guidance/d-quarantine/app1.html accessed 14 February 2020.

7. Li Z, Yi Y, Luo X et al. Development and clinical application of a rapid IgM-lgG combined antibody test for SARS-CoV-2 infection diagnosis. J Med Virol 2020;10:1518-1524

8. Xiao SY, Wu Y, Liu H. Evolving status of the 2019 novel coronavirus infection: proposal of conventional serologic assays for disease diagnosis and infection monitoring. J Med Virol 2020; 92: 464-467.

9. Yu-Lin L, Chia-Hung L, Po-Yu L, et al. Dynamics of anti-SARSCov-2 IgM and IgG antibodies among COVID-19 patients. J Infect 2020; 81(2): E55-E58. Doi.org/10.1016/j.jinf.2020.04.019

10. Testing Blueprint, Opening Up America Again https://www. whitehouse.gov/wp-content/uploads/2020/04/TestingBlueprint.pdf

11. Liua R, Hana H, Liub F, et al. Positive rate of RT-PCR detection of SARS-Cov2 infection in 4880 cases from one hospital in Wuhan, China, from Jan to Feb 2020. Clin Chim Acta 2020;505, 172175. Doi.org/10.1016/j.cca.2020.03.009

12. Ferguson MN, Laydon D, Nedjati-Gilani G, et al. Impact of non-pharmaceutical interventions (NPIs) to reduce COVID-19 mortality and healthcare demand. Imperial College London (1603-2020). Doi.org/10.25561/77482.

\section{Publish in The International}

Arabic Journal of Antimicrobial Agents

The Journal is an open access peer-reviewed journal that publishes scientific papers about all aspects of antimicrobials. The journal will publish original research articles, reviews, brief reports and case reports dealing with basic and clinical antibacterial agents, antiviral, antiprotozoals, antituberculuous, antifungal and antihelminthes agents. All manuscripts must be prepared in English, and are subject to a rigorous and fair peer-review process. Accepted papers will immediately appear online. The journal aims to advance the knowledge, attitude and the research of chemotherapy in the Arabic world in cooperation with international, national scientific and public societies as well as research centers with similar aims and objectives. 